\title{
Outcomes in lung transplantation after previous lung volume reduction surgery in a contemporary cohort
}

\author{
Leah Backhus, MD, ${ }^{\mathrm{a}}$ Jonathon Sargent, BS, ${ }^{\mathrm{b}}$ Aaron Cheng, MD, ${ }^{\mathrm{a}}$ Steven Zeliadt, $\mathrm{PhD}$, \\ Douglas Wood, MD, ${ }^{\mathrm{a}}$ and Michael Mulligan, $\mathrm{MD}^{\mathrm{a}}$
}

\begin{abstract}
Objectives: Lung volume reduction surgery (LVRS) provides palliation and improved quality of life in select patients with end-stage chronic obstructive pulmonary disease (COPD). The effect of previous LVRS on lung transplant outcomes has been inadequately studied. We report our experience in the largest single institution series of these combined procedures.
\end{abstract}

\begin{abstract}
Methods: The records of 472 patients with COPD undergoing lung transplantation or LVRS between 1995 and 2010 were reviewed. Outcomes of patients undergoing transplant after LVRS were compared with outcomes of patients undergoing transplant or LVRS alone. Survival was compared using log-rank tests and the KaplanMeier method.

Results: Demographics, comorbidities, and spirometry were similar at the time of transplantation. Patients who had undergone lung transplant after LVRS had longer transplant operative times (mean 4.4 vs 5.6 hours; $P=.020$ ) and greater hospital length of stay (mean 17.6 vs 29.1 days; $P=.005$ ). Thirty-day mortality and major morbidity were similar. Posttransplant survival was reduced for transplant after LVRS (median, 49 months; 95\% confidence interval [CI], 16, 85 months) compared with transplant alone (median, 96 months; 95\% CI, 82, 106 months; $P=.008$ ). The composite benefit of combined procedures, defined as bridge from LVRS to transplant of 55 months and posttransplant survival of 49 months (total 104 months), was comparable with survival of patients undergoing either procedure alone.
\end{abstract}

Conclusions: Lung transplant after LVRS leads to minimal additional perioperative risk. The reduced posttransplant survival in patients undergoing combined procedures is in contradistinction to reports from other smaller series. When determining the best surgical treatment for patients with more severe disease, the benefit of LVRS before transplant should be weighed against the consequence of reduced posttransplant survival. (J Thorac Cardiovasc Surg 2014;147:1678-83)

\section{Supplemental material is available online.}

Chronic obstructive pulmonary disease (COPD) is the third leading cause of death in the United States accounting for more than 130,000 deaths each year. ${ }^{1}$ Medical therapy and supportive care may improve symptoms and quality of life but are unable to reverse the course of the disease.

From the Division of Cardiothoracic Surgery, ${ }^{\text {a }}$ Department of Surgery, University of Washington; University of Washington School of Medicine ${ }^{\mathrm{b}}$; and Department of Health Services, ${ }^{\text {c }}$ University of Washington School of Public Health, Seattle, Wash.

Disclosures: Authors have nothing to disclose with regard to commercial support. Read at the 39th Annual Meeting of The Western Thoracic Surgical Association, Coeur d'Alene, Idaho, June 26-29, 2013.

Received for publication June 21, 2013; revisions received Sept 27, 2013; accepted for publication Jan 30, 2014; available ahead of print Feb 28, 2014.

Address for reprints: Leah Backhus, MD, Division of Cardiothoracic Surgery, Department of Surgery, University of Washington, 1959 NE Pacific St, Seattle, WA 98195 (E-mail: lbackhus@u.washington.edu).

0022-5223/\$0.00

Published by Elsevier Inc. on behalf of The American Association for Thoracic Surgery

http://dx.doi.org/10.1016/j.jtcvs.2014.01.045
For many patients, surgical intervention offers the best long-term outcomes. Surgical treatment of end-stage COPD consists of either lung volume reduction surgery (LVRS) or lung transplantation. Early results from LVRS in the 1990s, demonstrated significant improvements in pulmonary function tests (PFTs), dyspnea, and quality of life. $^{2,3}$ The results were further substantiated by the publication of the National Emphysema Treatment Trial (NETT), which refined patient selection and identified those who derive optimal benefit from this surgical therapy. ${ }^{4}$ Lung transplantation has also benefitted patients with limited life expectancy from end-stage COPD. It is associated with improved physical and social functioning, mental health, health perceptions, and patient-reported quality of life. ${ }^{5-8}$ However, not all patients with end-stage COPD meet the requirements for lung transplantation, and for those who do, the shortage of organ donors limits the number of lung transplants that can be performed. Thus, many have advocated for use of LVRS as a palliative surgical procedure in lieu of or as a bridge to lung transplantation. The posttransplant outcomes of these surgical procedures used in combination have been incompletely described. For this study, we reviewed our institutional 

Abbreviations and Acronyms
$\mathrm{COPD}=$ chronic obstructive pulmonary disease
$\mathrm{CI}=$ confidence interval
$\mathrm{FEV}_{1}=$ forced expiratory volume in 1 second
ICU $=$ intensive care unit
LAS = lung allocation score
LVRS $=$ lung volume reduction surgery
NETT $=$ National Emphysema Treatment Trial
PFT = pulmonary function tests
PVR = pulmonary vascular resistance
$\mathrm{RV} \quad=$ residual volume
$\mathrm{SD}=$ standard deviation

experience with patients with end-stage COPD who underwent LVRS, lung transplant, or both procedures to characterize posttransplant outcomes.

\section{METHODS}

\section{Patient Cohort and Variables}

The University of Washington Investigational Review Board for human subjects approved the study protocol. We reviewed the records of 473 adults with end-stage COPD undergoing lung transplantation or LVRS at our institution between 1995 and 2010. Patients presented to our multidisciplinary clinic for evaluation for either or both surgical procedures. A nurse coordinator screened patients who were further reviewed by 2 physicians before surgical consultation. The University of Washington was a participating site for the NETT and thus patients evaluated in the clinic during this time were also considered for enrollment in this trial. Patients undergoing LVRS after publication of the NETT results were selected based on NETT criteria. A total of 138 patients underwent lung transplantation and 335 patients underwent LVRS as their initial surgical therapy. Of the latter, 37 patients subsequently received a lung transplant. The record of 1 patient undergoing transplant after LVRS had insufficient follow-up data and was excluded from our analyses.

Clinical variables included patient demographics, PFTs, and preoperative comorbidities. The primary outcome of interest was overall survival after LVRS or transplantation. Secondary outcomes included perioperative and long-term complications after either procedure.

\section{LVRS and Lung Transplantation Surgical Techniques}

LVRS was performed via median sternotomy or video-assisted technique with sequential stapling and buttress. Areas of most severe hyperinflation, identified using preoperative imaging and intraoperative assessment, were selected for resection. Bilateral lung transplant was performed using a bilateral sequential technique via anterior thoracotomies with or without transverse sternotomy. Single lung transplant was performed via unilateral anterior thoracotomy. Cardiopulmonary bypass was used only in select cases.

\section{Statistical Analysis}

Descriptive statistics were expressed by median $(95 \%$ confidence interval $[\mathrm{CI}]$ ) or mean (standard deviation [SD]). Comparisons of categorical variables were made using the $\chi^{2}$ test or the Fisher exact test when applicable. Continuous variables were compared using the Student $t$ test or analysis of variance. Survival analysis was conducted using the Kaplan-Meier method and compared using the log-rank test. All statistical analyses were performed using STATA version 12.1 (Stata Corporation, College Station, Tex).

\section{RESULTS}

Patients undergoing LVRS alone were older (mean 63.3 years, SD 7.6 years) than patients who had lung transplantation after LVRS (mean 54.7 years, SD 6.9 years) or those undergoing lung transplantation alone (mean 57.8 years, SD 6.0 years $)(P=.024)$. Mean follow-up after LVRS was 19 months (SD 26 months) for LVRS alone. Mean follow-up after transplant was 50 months (SD 44 months) for combined LVRS and lung transplant, and 59 months (SD 38 months) for transplant alone (Table 1).

\section{Transplantation Outcomes}

When we compared posttransplant outcomes for those patients undergoing transplant after LVRS or transplant alone, we found similar pretransplant comorbidities and PFTs. Pretransplant pulmonary vascular resistance (PVR) was higher in those patients presenting for transplant after LVRS than patients undergoing transplant alone (2.2 vs 4.0 Woods units; $P=.002$ ) (Table 2). Transplant operative times were also longer for patients with transplant after LVRS (5.57 hours, SD 1.24 hours vs 4.40 hours, SD 1.20 hours; $P=.020$ ). All other intraoperative variables, including the need for cardiopulmonary bypass, estimated blood loss, and fluid and blood transfusion requirements, were similar between groups. Perioperative mortality was not significantly different between groups (30-day mortality $5.6 \%$ for transplant after LVRS vs $3.6 \%$ for transplant alone; $P=.599)$. Mean hospital length of stay was longer in patients undergoing transplant after LVRS (29.06 days, SD 32.82 days) compared with transplant only patients (17.57 days, SD 16.97 days; $P=.005$ ).

\section{LVRS Outcomes}

We further compared the surgical outcomes for patients undergoing LVRS alone with those undergoing LVRS and subsequent transplant (Table 3). Nearly all patients undergoing LVRS had bilateral procedures. In pre-LVRS PFTs, forced expiratory volume in 1 second $\left(\mathrm{FEV}_{1}\right)$ percentage predicted was significantly lower in the group undergoing subsequent transplant compared with patients undergoing LVRS alone $(22.39 \%$, SD $6.06 \%$ vs $27.02 \%$, SD $7.80 \%$, $P=.003)$. Residual volume (RV) percentage predicted was also higher in the group undergoing subsequent transplant $(262.4 \%$, SD $54.8 \%$ vs $229.9 \%$, SD $57.7 \%$, $P=.009)$ compared with LVRS alone. All other PFTs showed no difference between groups. The data were also examined by date of LVRS using 2003 as a cut-off coincident with the publication of the results of the NETT. Of patients undergoing LVRS during the pre-NETT era (1995-2002), $16 \%$ had subsequent lung transplant compared with $4 \%$ of patients undergoing LVRS post-NETT (2003-2010) 
TABLE 1. Demographics

\begin{tabular}{lcccc}
\hline \multicolumn{1}{c}{ Demographics, all } & Transplant & $\begin{array}{c}\text { LVRS }+ \\
\text { transplant }\end{array}$ & LVRS & $\begin{array}{c}\boldsymbol{P} \\
\text { value }\end{array}$ \\
\hline Total number & 138 & 36 & 298 & \\
Mean age at transplant, & $58(6)$ & $59(6)$ & & .413 \\
$\quad$ y (SD) & & & & \\
Mean age at LVRS, y (SD) & & $55(7)$ & $63(8)$ & $<.001$ \\
Sex & & & & .143 \\
$\quad$ Male, \% (n) & $44(60)$ & $53(19)$ & $54(159)$ & \\
Female, \% (n) & $57(78)$ & $47(17)$ & $46(138)$ & \\
Race & & & & .001 \\
$\quad$ White, \% & 93 & 94 & 82 & \\
$\quad$ Nonwhite, \% & 5 & 3 & 3 & \\
$\quad$ Unknown, \% & 2 & 3 & 15 & \\
ATD, \% (n) & $10(13)$ & $11(9)$ & $17(4)$ & .607 \\
Diabetes, \% (n) & $8(10)$ & $0(0)$ & & .094 \\
Hypertension, \% (n) & $37(49)$ & $34(12)$ & & .802 \\
Vascular disease, \% (n) & $2(3)$ & $6(2)$ & & .296 \\
Mean follow-up time, & $59(38)$ & $50(44)$ & $19(26)$ & \\
$\quad$ mo (SD) & & & &
\end{tabular}

$\overline{L V R S \text {, Lung volume reduction surgery; } S D \text {, standard deviation; } A T D, \alpha-1 \text { antitrypsin }}$ deficiency. *Follow-up time corresponds to follow-up after transplant for those patients undergoing transplant alone or transplant and LVRS, and corresponds to post-LVRS follow-up for patients undergoing LVRS alone.

$(P=.001)$. Mean time to listing for transplant for those undergoing subsequent transplant was 48.3 months (SD 30.1 months) and mean time to transplant was 54.6 months (SD 29.0 months) months after LVRS.

\section{Survival Analysis}

Survival analyses after LVRS demonstrated no difference in overall survival for those undergoing LVRS alone compared with LVRS with subsequent lung transplant $(P=.492)$ (Figure 1).

Posttransplant survival analyses demonstrated decreased survival for those patients undergoing transplant after LVRS compared with those undergoing transplant alone $(P=.008)$ (Figure 2). Posttransplant survival at 1, 5, and 10 years was $87 \%, 66 \%$, and $29 \%$, respectively, for the transplant alone group compared with $72 \%, 49 \%$, and $17 \%$, respectively, for the combined LVRS and transplant group. Median posttransplant survival for patients in the transplant alone group was 96 months $(95 \% \mathrm{CI}, 82,106$ months). Median post-LVRS survival was 103 months (95\% CI 84, 107 months) for patients undergoing LVRS alone. Composite survival for patients undergoing combined procedures was calculated as 55 months for bridge to transplant combined with a median posttransplant survival of 49 months ( $95 \%$ CI 16, 85 months) for a total benefit of 104 months (Figure E1).

\section{DISCUSSION}

COPD is a major cause of morbidity and mortality in the United States. Slow advancement in medical management
TABLE 2. Transplant outcomes

\begin{tabular}{|c|c|c|c|}
\hline Pretransplant variables & Transplant & $\begin{array}{l}\text { LVRS + } \\
\text { transplant }\end{array}$ & $\begin{array}{c}P \\
\text { value }\end{array}$ \\
\hline Mean $\mathrm{CO}, \mathrm{L} / \mathrm{min}(\mathrm{SD})$ & $5.9(1.7)$ & $5.7(1.6)$ & .555 \\
\hline Mean PCWP, mm Hg (SD) & $12.1(4.2)$ & $12.8(4.9)$ & .483 \\
\hline Mean PVR, Woods units (SD) & $2.2(0.9)$ & $4.00(2.8)$ & .002 \\
\hline Mean mPAP, mm Hg (SD) & $25.2(7.2)$ & $26.09(5.7)$ & .494 \\
\hline \multicolumn{4}{|c|}{ Pretransplant PFTs, mean $\%$ predicted (SD) } \\
\hline $\mathrm{FEV}_{1}$ & $19.9(5.5)$ & $19.1(5.3)$ & .414 \\
\hline TLC & $132.5(35.5)$ & $122.2(19.6)$ & .306 \\
\hline $\mathrm{RV}$ & $260.1(104.0)$ & $238.1(70.3)$ & .447 \\
\hline Dlco & $30.4(13.5)$ & $29.4(8.2)$ & .760 \\
\hline $\mathrm{PCO}_{2}$ & $50.0(11.8)$ & $46.3(10.1)$ & .092 \\
\hline \multicolumn{4}{|l|}{ Intraoperative variables } \\
\hline Cardiopulmonary bypass, $\%(\mathrm{n})$ & $15.8(21)$ & $8.3(3)$ & .256 \\
\hline Mean surgery time, $\mathrm{h}(\mathrm{SD})$ & $4.4(1.2)$ & $5.6(1.2)$ & .020 \\
\hline Mean EBL, mL (SD) & $462.0(237.6)$ & $741.7(1056.8)$ & .134 \\
\hline Mean volume of fluids, L (SD) & $2.3(1.3)$ & $2.8(1.0)$ & .258 \\
\hline \multicolumn{4}{|l|}{ Short-term outcomes } \\
\hline $\begin{array}{l}\text { Mean hospital length of stay, } \\
\text { d (SD) }\end{array}$ & $17.6(17.0)$ & $29.1(32.8)$ & .005 \\
\hline Mean ICU length of stay, $d(S D)$ & $7.9(12.9)$ & $6.2(6.2)$ & .545 \\
\hline Mean length of intubation, $d(S D)$ & $3.8(10.7)$ & $5.9(19.9)$ & .477 \\
\hline Lean length of chest tube, $d$ (SD) & $13.5(12.9)$ & $16.3(20.4)$ & .436 \\
\hline Thrombolytic events, \% (n) & $8.9(12)$ & $8.3(3)$ & .917 \\
\hline Anastomotic dehiscence, $\%(\mathrm{n})$ & $5.1(7)$ & $8.3(3)$ & .461 \\
\hline Bronchopleural fistula, \% (n) & $2.2(3)$ & $2.8(1)$ & .845 \\
\hline Prolonged air leak, \% (n) & $16.3(22)$ & $13.9(5)$ & .725 \\
\hline Phrenic nerve injury, $\%(\mathrm{n})$ & $2.2(3)$ & $5.6(2)$ & .292 \\
\hline Tracheostomy, \% (n) & $2.9(4)$ & $5.6(2)$ & .447 \\
\hline Atrial fibrillation, $\%(\mathrm{n})$ & $46.7(63)$ & $38.9(14)$ & .405 \\
\hline 30-d mortality, \% (n) & $3.6(5)$ & $5.6(2)$ & .599 \\
\hline
\end{tabular}

LVRS, Lung volume reduction surgery; $C O$, cardiac output; $S D$, standard deviation; $P C W P$, pulmonary capillary wedge pressure; $P V R$, pulmonary vascular resistance; $m P A P$, mean pulmonary arterial pressure; $P F T$, pulmonary function test; $F E V_{l}$, forced expiratory volume in 1 second; $T L C$, total lung capacity; $R V$, residual volume; $D L C O$, diffusion capacity of carbon monoxide; $\mathrm{PCO}_{2}$, partial pressure of carbon dioxide; $E B L$, estimated blood loss; $I C U$, intensive care unit.

of COPD led to initial enthusiasm for surgical alternatives. ${ }^{9}$ Results from the first study of a large number of patients undergoing surgical management of COPD via LVRS, published in 1977 , showed a $21 \%$ mortality rate. Since then, the LVRS technique has been further refined leading to improvements in symptoms, patient-reported quality of life, and increased overall survival in properly selected patients. $2,4,10-16$ Lung transplantation also offers significant survival and quality of life advantages in patients with limited life expectancy presenting with endstage lung disease. ${ }^{6-8,17,18}$ However, more widespread use of lung transplantation is restricted by limited organ availability. Consequently, wait-list mortality for lung transplant for all diagnoses is 15.7 per 100 wait-list years. ${ }^{19}$ Providers have been biased toward offering LVRS over lung transplantation to all qualifying patients presenting with end-stage COPD largely because of this sobering fact combined with the known consequences of long-term 
TABLE 3. LVRS outcomes

\begin{tabular}{|c|c|c|c|}
\hline Pre-LVRS variables & LVRS & $\begin{array}{l}\text { LVRS + } \\
\text { transplant }\end{array}$ & $\begin{array}{c}P \\
\text { value }\end{array}$ \\
\hline \multicolumn{4}{|l|}{ Pre-LVRS PFTs, mean \% predicted (SD) } \\
\hline $\mathrm{FEV}_{1}$ & $27.0(7.8)$ & $22.4(6.1)$ & .003 \\
\hline TLC & $133.3(224.2)$ & $131.7(20.1)$ & .759 \\
\hline RV & $229.9(57.7)$ & $262.4(54.8)$ & .009 \\
\hline DlCo & $33.2(10.8)$ & $31.9(12.8)$ & .641 \\
\hline $\mathrm{PCO}_{2}$ & $43.4(5.5)$ & $43.8(7.9)$ & .795 \\
\hline Date of LVRS, \% (n) & & & .001 \\
\hline 1995-2002 & $84(164)$ & $16(30)$ & \\
\hline $2003-2010$ & $96(134)$ & $4(6)$ & \\
\hline LVRS laterality, \% & & & .643 \\
\hline Right & 1 & 0 & \\
\hline Left & 2 & 0 & \\
\hline Bilateral & 97 & 100 & \\
\hline Time from LVRS to listing, mo (SD) & & $48(30)$ & \\
\hline $\begin{array}{l}\text { Time from LVRS to transplant, } \\
\text { mo (SD) }\end{array}$ & & $55(29)$ & \\
\hline
\end{tabular}

immunosuppression. ${ }^{20}$ However, mortality for patients with COPD is less than 10 per 100 wait-list years and represents the lowest of all diagnosis groups. ${ }^{19}$ Further support for LVRS bias has come from reports of outcomes for patients undergoing transplant after LVRS being comparable with those undergoing transplant alone. ${ }^{20,21}$ One study examined patients undergoing combined procedures from 1993 to 1997 and included 15 patients, only 7 of whom underwent transplant ipsilateral to their LVRS procedure. ${ }^{21}$ Another study examined the United Network for Organ Sharing data and identified 50 patients undergoing combined procedures all in the pre-NETT era from 1999 to 2002 . Only $28 \%$ of patients underwent bilateral

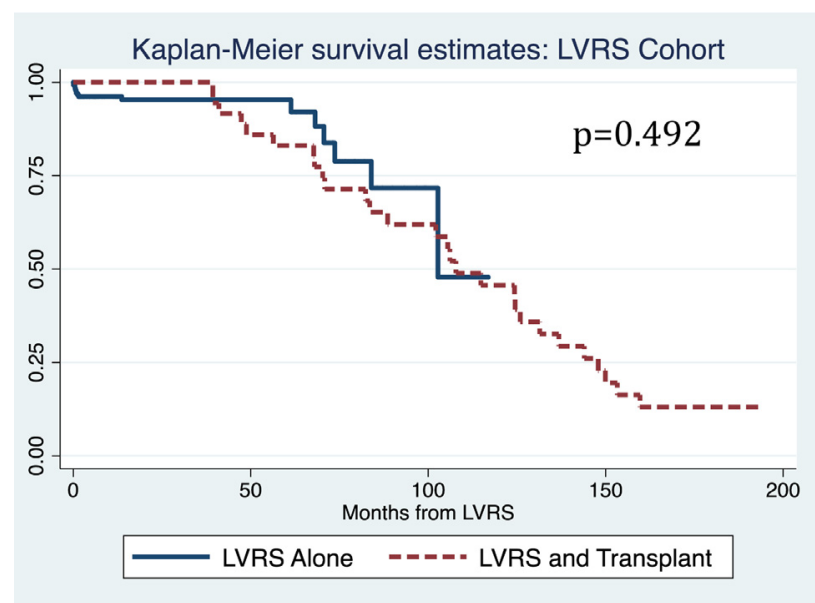

FIGURE 1. Lung volume reduction surgery survival: Kaplan-Meier survival estimates. LVRS, Lung volume reduction surgery.

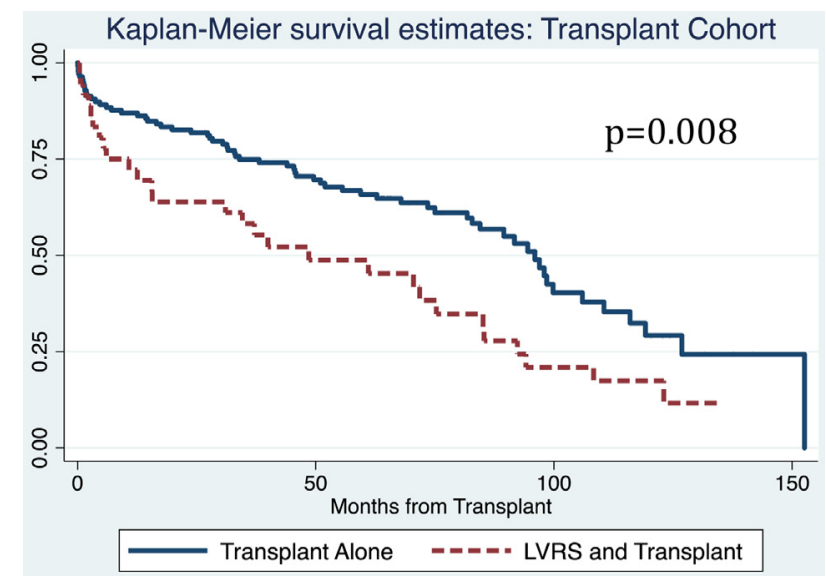

FIGURE 2. Transplant survival: Kaplan-Meier survival estimates. LVRS, Lung volume reduction surgery.

lung transplantation and laterality of LVRS was not discussed. ${ }^{22}$ Neither study identified differences in perioperative outcomes; however, small patient numbers undergoing ipsilateral procedures and lack of patient selection after the publication of the NETT limited both studies.

Our findings demonstrated differences in short-term and long-term posttransplant outcomes for patients undergoing both procedures compared with transplant alone. Although clinically important, these differences did not reach statistical significance. Where our findings differ from previous published reports, however, is in demonstrating reduced posttransplant survival for patients undergoing transplant after LVRS. The reduced posttransplant survival in patients undergoing combined procedures might be partially explained by the longer surgical time usually because of extensive adhesions and longer dissection requirements. Similarly, longer hospital length of stay may also be a crude measure pointing to the higher acuity of these patients and may contribute to their reduced early survival. However, patients undergoing transplant after LVRS also presented with PFTs at the time of LVRS that were much closer to the PFTs of patients undergoing transplant alone. Although the mean values for $\mathrm{FEV}_{1}, \mathrm{RV}$, diffusion capacity of carbon monoxide, and total lung capacity were all outside the high-risk category by the NETT criteria for LVRS, they still represented more severe disease at the time of initial presentation. The equivalent post-LVRS survival for patients undergoing LVRS alone versus transplant after LVRS may be a reflection of the added value of transplant in rescuing these more severely affected patients from otherwise reduced survival in the absence of lung transplantation. A study examining outcomes of 99 patients who were candidates for both procedures described 15 patients who went on to have lung transplantation at a mean time of 45.6 months. The investigators found that these patients were younger, more impaired (reduced $\mathrm{FEV}_{1}$, increased RV, and disease more predominantly in the lower lobe) and 
had less benefit from their LVRS procedure than the others who did not receive transplantation. ${ }^{23}$ Another study reported experience from 27 patients undergoing transplant after previous LVRS. The investigators reported a mean bridge time of 29.7 months and examined posttransplant survival for patients undergoing both procedures by subdividing them into those who did well after LVRS compared with those who did not as shown by improvement in $\mathrm{FEV}_{1}$ and body mass index. The investigators did not compare preoperative pulmonary function or posttransplant survival with patients undergoing transplant alone as we did in this study. They do report non-upper lobe predominant emphysema distribution associated with poor outcomes after LVRS and subsequent poor outcomes after lung transplantation. ${ }^{24}$ Others have also conceded that patients who benefit most from LVRS are those with less severe disease at presentation. ${ }^{20}$ These findings underscore the importance of patient selection at the time of initial presentation for LVRS in predicting posttransplant outcomes.

Our study is limited by incomplete data for the LVRS group and for long-term follow-up. Other factors not captured in this dataset include acute rejection episodes and bronchiolitis obliterans, which might also help explain the observed difference in survival. We did not have information regarding the distribution of emphysema, which is critical for determining the estimated benefit of LVRS. Our study also included patients evaluated for LVRS both before (1995-2002) and after (2003-2010) publication of the results of NETT. We did examine our results using these time cut-offs and found that the difference in survival persisted (data not shown). Also during the study period, the lung allocation score (LAS) was introduced, however under the LAS, patients with emphysema have been deprioritized for transplant thus one would expect to see a potential decrease in the number of transplants being performed for COPD and a potential increase in the number of LVRS procedures, which was not observed. Nonetheless, improvements in patient selection for candidacy for LVRS may indeed have played a role in our reported outcomes.

On a larger scale, the benefits of the use of combined procedures must be evaluated in the context of overall benefits as well as health care resource allocation. We defined composite survival as the bridge time between LVRS and subsequent lung transplantation combined with posttransplant survival. Patients undergoing both procedures had composite survival similar to survival after either procedure alone, but at the expense of reduced posttransplant survival and use of 2 surgical procedures. This difference is not trivial. Although it can be argued that the end result of equivalent survival justifies the means, we would counter that this justification deserves closer scrutiny. Clearly there are substantial benefits to delaying entry into the world of posttransplant care, with concomitant risks associated with immunosuppression. However, if the more severely affected patient with end-stage COPD eventually requires a lung transplant even after LVRS in order to receive optimal benefit, that patient might be better served with lung transplant as the single surgical intervention. Patients undergoing lung transplantation do experience a higher level of functional status, greater improvements in airflow obstruction, dyspnea, and exercise tolerance compared with patients undergoing LVRS and these effects are more durable than with LVRS. ${ }^{25}$ Overall, however, the cost of lung transplant is roughly twice that of LVRS at 2 years. Thus, if we are to consider the benefits of both surgical procedures as additive, so too are the costs.

Our findings are particularly relevant given the increasing costs of health care with renewed emphasis on cost containment and advocacy. Some encourage pushing the limits of LVRS by offering it to more marginal patients including those defined as high risk by the NETT criteria. ${ }^{23}$ The choice of surgical modality is straightforward in some patients. Patients who do not meet the high-risk criteria for NETT and otherwise do not straddle the line between LVRS and pretransplant clinical parameters should be offered LVRS as their definitive surgical therapy. In many cases, improvement in symptoms and quality of life may be sufficient to defer or eliminate the need for lung transplant altogether. Likewise, patients with depressed lung function too severe for consideration of LVRS should be referred directly to transplantation. For patients who have marginal function, but otherwise meet the criteria for LVRS, particularly younger patients, lung transplant might be offered with similar outcomes and maximal benefit conferred per organ used. Few patients potentially fall into this category as they likely represent a small subgroup of patients who should be best served by a single surgical intervention for management of their COPD.

\section{References}

1. American Lung Association. Epidemiology and Statistics Unit. Trends in COPD: Morbidity and Mortality: American Lung Association Epidemiology and Statistics Unit Research and Program Services Division; 2013. Available at: http://www. lung.org/finding-cures/our-research/trend-reports/copd-trend-report.pdf. Accessed March 13, 2013

2. Cooper JD, Patterson GA, Sundaresan RS, Trulock EP, Yusen RD, Pohl MS, et al. Results of 150 consecutive bilateral lung volume reduction procedures in patients with severe emphysema. J Thorac Cardiovasc Surg. 1996;112:1319-29; discussion 1329-30.

3. Cooper JD, Patterson GA. Lung volume reduction surgery for severe emphysema. Semin Thorac Cardiovasc Surg. 1996;8:52-60.

4. Fishman A, Martinez F, Naunheim K, Piantadosi S, Wise R, Ries A, National Emphysema Treatment Trial Research Group. A randomized trial comparing lung-volume-reduction surgery with medical therapy for severe emphysema. N Engl J Med. 2003;348:2059-73.

5. TenVergert EM, Vermeulen KM, Geertsma A, van Enckevort PJ, de Boer WJ, van der Bij W, et al. Quality of life before and after lung transplantation in patients with emphysema versus other indications. Psychol Rep. 2001;89:707-17.

6. Gross CR, Savik K, Bolman RM III, Hertz MI. Long-term health status and quality of life outcomes of lung transplant recipients. Chest. 1995;108:1587-93.

7. Limbos MM, Joyce DP, Chan CK, Kesten S. Psychological functioning and quality of life in lung transplant candidates and recipients. Chest. 2000;118:408-16.

8. Vermeulen KM, Groen H, van der Bij W, Erasmus ME, Koeter GH, TenVergert EM. The effect of bronchiolitis obliterans syndrome on health related quality of life. Clin Transplant. 2004;18:377-83. 
9. Delarue NC, Woolf CR, Sanders DE, Pearson FG, Henderson RD, Cooper JD, et al. Surgical treatment for pulmonary emphysema. Can J Surg. 1977;20:222-31.

10. Lowdermilk GA, Keenan RJ, Landreneau RJ, Hazelrigg SR, Bavaria JE, Kaiser LR, et al. Comparison of clinical results for unilateral and bilateral thoracoscopic lung volume reduction. Ann Thorac Surg. 2000;69:1670-4.

11. Benzo R, Farrell MH, Chang CC, Martinez FJ, Kaplan R, Reilly J, et al. Integrating health status and survival data: the palliative effect of lung volume reduction surgery. Am J Respir Crit Care Med. 2009;180:239-46.

12. Berger RL, Wood KA, Cabral HJ, Goodnight-White S, Ingenito EP, Gray A, et al. Lung volume reduction surgery: a meta-analysis of randomized clinical trials. Treat Respir Med. 2005;4:201-9.

13. Naunheim KS, Wood DE, Mohsenifar Z, Sternberg AL, Criner GJ, DeCamp MM, et al. Long-term follow-up of patients receiving lung-volume-reduction surgery versus medical therapy for severe emphysema by the National Emphysema Treatment Trial Research Group. Ann Thorac Surg. 2006;82:431-43.

14. Criner GJ, Belt P, Sternberg AL, Mosenifar Z, Make BJ, Utz JP, et al. Effects of lung volume reduction surgery on gas exchange and breathing pattern during maximum exercise. Chest. 2009;135:1268-79.

15. Kaplan RM, Ries AL, Reilly J, Mohsenifar Z. Measurement of health-related quality of life in the national emphysema treatment trial. Chest. 2004;126:781-9.

16. Flaherty KR, Kazerooni EA, Curtis JL, Iannettoni M, Lange L, Schork MA, et al. Short-term and long-term outcomes after bilateral lung volume reduction surgery : prediction by quantitative CT. Chest. 2001;119:1337-46.

17. Goetzmann L, Scheuer E, Naef R, Vetsch E, Buddeberg C, Russi EW, et al. Psychosocial situation and physical health in 50 patients $>1$ year after lung transplantation. Chest. 2005;127:166-70.
18. Lanuza DM, Lefaiver C, McCabe M, Farcas GA, Garrity E Jr. Prospective study of functional status and quality of life before and after lung transplantation. Chest. 2000;118:115-22.

19. Valapour M, Paulson K, Smith JM, Hertz MI, Skeans MA, Heubner BM, et al, OPTN/SRTR 2011 Annual Data Report: lung. Am J Transplant. 2013;13(Suppl 1):149-77.

20. Tutic M, Lardinois D, Imfeld S, Korom S, Boehler A, Speich R, et al. Lung-volume reduction surgery as an alternative or bridging procedure to lung transplantation. Ann Thorac Surg. 2006;82:208-13; discussion 213.

21. Burns KE, Keenan RJ, Grgurich WF, Manzetti JD, Zenati MA. Outcomes of lung volume reduction surgery followed by lung transplantation: a matched cohor study. Ann Thorac Surg. 2002;73:1587-93.

22. Nathan SD, Edwards LB, Barnett SD, Ahmad S, Burton NA. Outcomes of COPD lung transplant recipients after lung volume reduction surgery. Chest. 2004;126: 1569-74.

23. Meyers BF, Yusen RD, Guthrie TJ, Patterson GA, Lefrak SS, Davis GE, et al Results of lung volume reduction surgery in patients meeting a national emphysema treatment trial high-risk criterion. J Thorac Cardiovasc Surg. 2004;127 829-35.

24. Senbaklavaci O, Wisser W, Ozpeker C, Marta G, Jaksch P, Wolner E, et al Successful lung volume reduction surgery brings patients into better condition for later lung transplantation. Eur J Cardiothorac Surg. 2002;22: 363-7.

25. Weinstein MS, Martin UJ, Crookshank AD, Chatila W, Vance GB, Gaughan JP, et al. Mortality and functional performance in severe emphysema after lung volume reduction or transplant. COPD. 2007;4:15-22. 


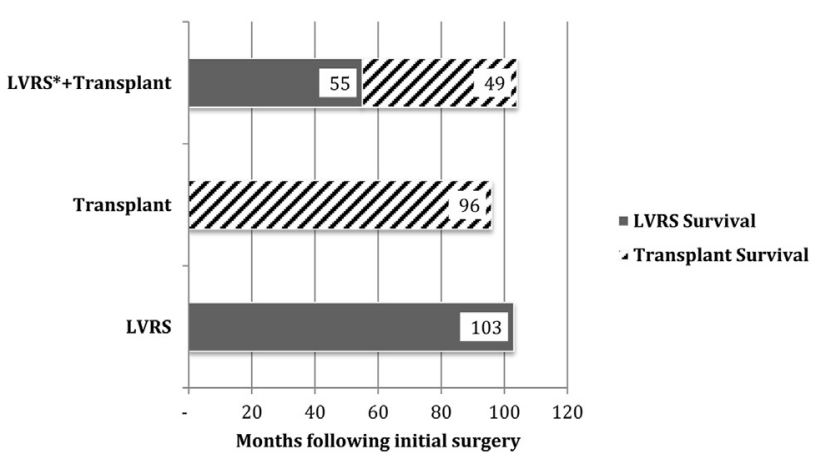

FIGURE E1. Composite survival benefit. *Lung volume reduction surgery survival for combined surgical treatment listed as time from lung volume reduction surgery to time to transplant. LVRS, Lung volume reduction surgery. 